\title{
Precolumn Fluorescence Derivatization of Nucleosides for Mono- and Oligonucleotides
}

\author{
Hiroaki Nagaoka*, Hitoshi Nohta*, Mikihiko SaIto** and Yosuke OHKURA* \\ *Faculty of Pharmaceutical Sciences, Kyushu University 62, Maidashi, Fukuoka 812, Japan \\ **Dojindo Laboratories, Tabaru 2025-5, Mashiki-machi, Kumamoto 861-22, Japan
}

\begin{abstract}
Keywords Fluorescence derivatization, 2-(5-chlorocarbonyl-2-oxazolyl)-5,6-methylenedioxybenzofuran, mononucleotide, oligonucleotide, high-performance liquid chromatograhy
\end{abstract}

The determination of mono- and oligonucleotides has been required not only for their characterization ${ }^{1}$, but also for evaluating their physiological roles. ${ }^{2,3}$

We previously reported that 2-(5-chlorocarbonyl-2oxazolyl)-5,6-methylenedioxybenzofuran (OMB-COCl) reacted in a benzene-pyridine mixture with all kinds of nucleosides at the 5'-hydroxyl group to produce the corresponding fluorescent esters, which could be separated by reversed-phase high-performance liquid chromatography (HPLC). ${ }^{4}$ The purpose of this study was to establish an HPLC method for the quantification of mono- and oligonucleotides by modifying the abovementioned techniques. The conditions of the derivatization reaction and HPLC separation were investigated using adenosine-3'-monophosphate (Ap), uridine-3'monophosphate (Up), 2'-deoxyadenosine-3'-monophosphate (dAp) and thymidine- $3^{\prime}$-monophosphate (Tp) as model mononucleotides, $2^{\prime}$-deoxyadenylyl $\left(3^{\prime}-5^{\prime}\right)$ thymidine $[\mathrm{d}(\mathrm{AT})]$ as a dinucleotide and $2^{\prime}$-deoxyadenylyl $\left(3^{\prime}\right.$ $\left.5^{\prime}\right)-2^{\prime}$-deoxyguanylyl $\left(3^{\prime}-5^{\prime}\right)-2^{\prime}$-deoxycytidylyl $\left(3^{\prime}-5^{\prime}\right)$ thymidine $[\mathrm{d}(\mathrm{AGCT})]$ as a tetranucleotide.

\section{Experimental}

\section{Chemicals and HPLC system}

OMB-COCl was obtained from Dojindo Laboratories (Kumamoto, Japan). Ap, cytidine-3'-monophosphate (Cp), guanosine-3'-monophosphate (Gp), Up, dAp, 2'deoxycytidine-3'-monophosphate (dCp), 2'-deoxyguanosine-3'-monophosphate (dGp), Tp, and $d(A T)$ were purchased from Sigma (St. Louis, MO, USA) and $\mathrm{d}(\mathrm{AGCT})$ from Takara Shuzo (Kyoto, Japan).

The HPLC system and its operation conditions were the same as described previously ${ }^{4}$, except that the mobile phase was a mixture of acetonitrile and a $50 \mathrm{mM}$ McIlvaine buffer (a solution containing $50 \mathrm{mM}$ citric acid and $50 \mathrm{mM}$ sodium dihydrogen phosphate, $\mathrm{pH}$ 3.0) $(3: 7, \mathrm{v} / \mathrm{v})$.

\section{Derivatization procedure}

An aqueous mixture of nucleotides $(0.1-1.0 \mathrm{ml})$ placed in a screw-capped vial $(3.5 \mathrm{ml})$ was lyophilized. To the lyophilizate was added a mixture of pyridine and $3 \mathrm{mM}$ OMB-COCl in benzene $(1: 3, \mathrm{v} / \mathrm{v})(0.5 \mathrm{ml})$. The vial was tightly closed and heated at $100^{\circ} \mathrm{C}$ for $90 \mathrm{~min}$ in the dark. After cooling, the reaction mixture was dried in a stream of nitrogen at $37^{\circ} \mathrm{C}$; the residue was dissolved in the mobile phase for HPLC. The resulting solution $(20 \mu \mathrm{l})$ was subjected to HPLC.

\section{Results and Discussion}

Higher temperatures allowed the derivatization reaction to proceed more rapidly in the $60-120^{\circ} \mathrm{C}$ range. At $100^{\circ} \mathrm{C}$ the peak heights reached maxima upon heating for $60-120 \mathrm{~min}$; heating at $100^{\circ} \mathrm{C}$ for $90 \mathrm{~min}$ was employed in the procedure.

Pyridine, an accelerator of the derivatization reaction, provided maximum peak heights for the nucleotides at concentrations of $2.5-4.1 \mathrm{M}$ in the reaction mixture; 3.1 $\mathrm{M}$ was used in the procedure. The most intense peaks for the nucleotides (concentrations, $8.75 \mathrm{nmol}$ $\mathrm{ml}^{-1}$ each in the reaction mixture) were obtained at OMB$\mathrm{COCl}$ concentrations of $2-10 \mathrm{mM} ; 3 \mathrm{mM}$ was used. $\mathrm{OMB}-\mathrm{COCl}$ afforded singel peaks for the respective nucleotides under the recommended derivatization conditions; MOB-COCl possibly reacted with the nucleotides at the 5'-hydroxyl group.

The fluorescent products from the six nucleotides could be satisfactorily separated by reversed-phase

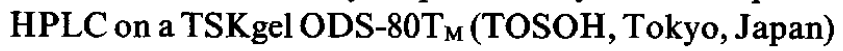
with isocratic elution using a mixture of acetonitrile and a $50 \mathrm{mM}$ Mcllvaine buffer (pH 3.0) $(3: 7, \mathrm{v} / \mathrm{v})$. Figure 1 shows a typical chromatogram obtained with the fluorescent products from the six nucleotides under the recommended HPLC conditions (for the retention times see Table 1).

The relationships between the peak heights and the 


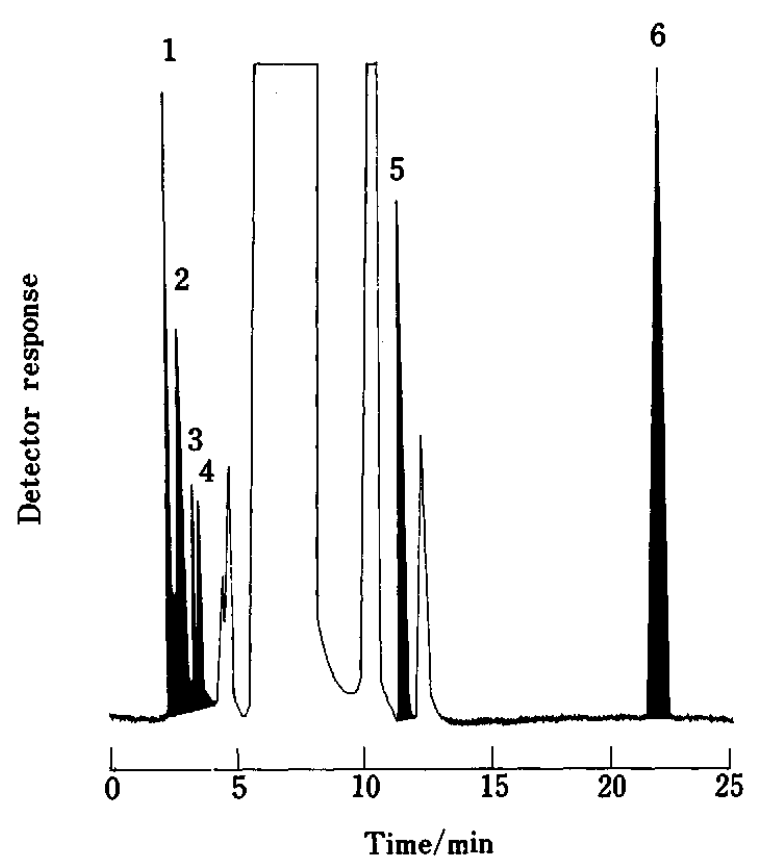

Fig. 1 Chromatogram of the fluorescent products from nucleotides. The peaks for nucleotides are shaded. Peaks: $1=\mathrm{Up}, \quad 2=\mathrm{Ap}, \quad 3=\mathrm{Tp}, \quad 4=\mathrm{dAP}, \quad 5=\mathrm{d}(\mathrm{AT}), \quad 6=\mathrm{d}(\mathrm{AGCT})$, others $=$ the reagent blank. Concentrations (on column): 35 pmol each.

amonunts of nucleotides (10 species, listed in Table 1) were linear up to $1 \mathrm{nmol}$ per $20-\mu \mathrm{l}$ injection volume, respectively. The precision was established by repeated determinations $(n=10)$ using a mixture of the nucleotides (concentrations, $8.75 \mathrm{nmol} \mathrm{ml}^{-1}$ each). The relative standard deviations (\%) were 1.4(Ap), 0.6(Cp), 1.5(Gp), 2.0(Up), 1.3(dAp), 1.5(dCp), 1.8(dGp), 3.0(Tp), 4.8[d(AT)] and 3.0[d(AGCT)]. The detection limits were $0.8-$ $6 \mathrm{pmol}$ per $20-\mu \mathrm{l}$ injection volume (Table 1 ).
Table 1 Retention times and detection limits $(S / N=3)$ of the fluorescent products from nucleotides

\begin{tabular}{lcc}
\hline Nucleotide & Retention time/min & $\begin{array}{c}\text { Detection limit } \\
\text { (pmol on column) }\end{array}$ \\
\hline Ap & 2.8 & 4.0 \\
Cp & 2.6 & 4.5 \\
Gp & 2.6 & 5.0 \\
Up & 2.4 & 3.0 \\
dAp & 3.8 & 3.8 \\
dCp & 3.8 & 4.7 \\
dGp & 3.5 & 6.0 \\
Tp & 3.0 & 3.0 \\
d(AT) & 11.8 & 1.2 \\
d(AGCT) & 22.3 & 0.8 \\
\hline
\end{tabular}

The methold should be usable for the determination of those nucleotides derived from polynucleotides by a nuclease-mediated reaction.

This work was partially supported by a Grant-in-Aid for Scientific Research from the Ministry of Education, Science and Culture of Japan.

\section{References}

1. W. T. Ruyechan, T. A. Casey, W. Reinhold, A. C. Wellman, S. E. Straus and J. Hay, J. Gen. Virol, 66, 43 (1985).

2. R. J. Haslam and M. M. L. Davidson, Nature [London], 313, 821 (1985).

3. M. M. Barrowman, S. Cockcroft and B. D. Gompers, Nature [London], 319, 821 (1986).

4. H. Nagaoka, H. Nohta, M. Saito and Y. Ohkura, Anal. Sci., 8, 345 (1992).

(Received February 5, 1992) (Accepted May 20, 1992) 